\title{
Imaginários da portugalidade: análise de discursos de imigrantes portugueses em Belém do Pará- Brasil
}

\section{Imaginaries of portugality: discourse analysis of portuguese immigrants in Belém do Pará - Brazil}

Maria Manuel Baptista - Professora e Diretora do Programa Doutoral em Estudos Culturais das Universidades de Aveiro e do Minho, Portugal. E-mail: mbaptista@ua.pt

\section{Resumo}

O presente estudo centra-se nas identidades e imaginários de imigrantes portugueses na cidade de Belém do Pará. Considerada como 'a mais portuguesa das cidades brasileiras', Belém foi recebendo, desde os finais do século XIX e durante todo o século XX importantes fluxos migratórios, entre os quais se destacam os portugueses (além de sírio-libaneses, japoneses, judeus, espanhóis, italianos, entre outros).Utilizando um paradigma teórico, que parte dos Estudos Culturais, a presente abordagem utiliza uma análise qualitativa que intitulámos como hermenêutica mítica dos imaginários culturais. $\mathrm{Na}$ segunda parte do estudo elaboramos a noção de imaginário cultural com que pretendemos analisar os discursos dos nossos sujeitos, sobre os quais incidiu a nossa investigação de campo: cinco famílias alargadas de portugueses imigrantes em Belém do Pará (quer de primeira quer de segundas e terceiras gerações) e as respetivas representações de Portugal e da portugalidade compreendidas a partir das suas histórias de vida (recolhidas em entrevistas coletivas aprofundadas), atravessadas pelos seus imaginários e identidades migrantes.

\section{Palavras-chave}

Imigrantes. Portugal. Belém do Pará. Estudos Culturais. Imaginário.

\begin{abstract}
The present study focuses on the identities and imaginaries of Portuguese emigrants in the city of Belém do Pará. Considered as 'the most Portuguese of the Brazilian cities', Belém has been receiving important migratory flows since the end of the 19th century and throughout the 20th century, among them the Portuguese (besides Syrian-Lebanese, Japanese, Jews, Spaniards, Italians, and others). Using the theoretical paradigm of Cultural Studies, the present approach uses a qualitative analysis that we call 'mythical hermeneutics of cultural imaginaries'. In the second part of the study we elaborate the notion of cultural imaginary with which we intend to analyse the discourses of our subjects, on which our field research focused: five extended families of Portuguese immigrants in Belém do Pará (either first or second or even third generations) and their representations of Portugal and of Portugal understood from their life histories (collected in in-depth collective interviews), crossed by their imaginaries and migrant identities.
\end{abstract}

\section{Keywords}

Imigrants. Portugal. Belém do Pará. Cultural Studies. Imaginary. 


\section{INTRODUÇÃO}

A pesquisa que aqui apresentamos partiu da constatação da inexistência de trabalhos sobre imigrantes portugueses, que se debruçassem sobre os imaginários da portugalidade na atualidade. Com efeito, os estudos sobre emigração concentram-se em dados demográficos, frequentemente numa perspetiva histórica de grandes fluxos migratórios e são muito raros aqueles que procuram estudar os discursos dos sujeitos migrantes, em primeira mão, e ainda menos aqueles que analisam os imaginários da portugalidade que os atravessam.

Por outro lado, a cidade de Belém, tem sido objeto de múltipla investigação nos últimos anos, mas nenhuma incidindo sobre os imaginários das populações de imigrantes portugueses. $O$ interesse dos investigadores na cidade tem-se espraiado pela sua geografia e ambiente, bem como pela história e arte. Apesar de existir um grupo de Estudos Culturais na Amazónia, tanto quanto pudemos compreender, a sua atividade não se tem dirigido nem para esta população, nem para esta temática.

No presente estudo, partimos precisamente dos Estudos Culturais, utilizando um desenho de investigação qualitativo, que intitulámos como hermenêutica mítica dos imaginários culturais.

As conclusões a que chegámos apontam para a construção de imaginários da portugalidade profundamente marcados por imaginários míticos tanto de Portugal como da portugalidade, com laivos muito pronunciados de messianismo utópico muito próximos do pensamento judaico-cristão, uma constante da cultura portuguesa ao longo dos últimos séculos, dentro e fora do território nacional.

\section{EMIGRAÇÃO PORTUGUESA PARA BELÉM DO PARÁ NO SÉCULO $\mathrm{XX}$}

Após o levantamento bibliográfico que realizámos, registamos, a partir de outras áreas científicas, que não os Estudos Culturais, projetos e linhas de pesquisa diversos como, entre outros, "Migração Internacional Pan-Amazôniana" (ARAGÓN, 2009), "Nas duas margens. Os portugueses no Brasil" (SOUSA, MATOS, \& MATOS, 2009), "Belém de águas e ilhas - 400 anos: saberes, usos, memórias e história da insularidade" (TAVARES,2014) e ainda "Cultura material, patrimônio e sociedade" (PACHECO, 2012-14), que têm procurado estudar a história e o património da cidade de Belém onde, no final do século XIX e inícios do século XX, se instalou uma importante comunidade de imigrantes portugueses. 
Neste âmbito, registamos recentemente outros trabalhos científicos importantes como "Pátria minha: portugueses e brasileiros no Grão-Pará" (SARGES, 2009-2011), "Entre fluxos, fontes e trajetórias: imigração portuguesa para uma capital da Amazônia (1850-1920)" (CANCELA \& COSME, 2016), ou mais longinquamente (SARGES, 2004) "Exposição Belém dos Imigrantes: história e memória”. Ainda com alguma conexão com o nosso objeto de estudo, por tratar de emigração ibérica para Belém, refira-se o projeto de pesquisa "Propaganda, migração e trocas culturais: Pará e Espanha (XIX/XX)" (SARGES, 2012-2014) ou ainda "Portugal e as migrações da Europa do sul para a América do sul" (SOUSA et al., 2014).

Mais diretamente relacionada com o nosso objeto de pesquisa encontra-se, porém, uma tese de doutoramento apresentada por Marcos Antônio de Carvalho, em 2011, na Faculdade de Letras da Universidade do Porto, intitulada "Bebendo açaí, comendo bacalhau: Perfil e práticas da sociabilidade lusa em Belém do Pará entre finais do século XIX e início do século XX” (CARVALHO, 2011).

Nela, o autor afirma: "o imigrante que fez opção pela conformação de uma identidade dupla (lusa e brasileira) esforçou-se por ter, nessa condição de imigrante, a permanência de estilos de vida semelhantes aqueles que possuíam na sua terra de origem. Por outro lado, identifica-se ainda o experimento de uma nova postura, adequando seu modus vivendi aos dos indivíduos da sociedade que agora os tinha adotado ou acolhido" (CARVALHO, 2011:160).

Neste hibridismo cultural em que passa a viver, o imigrante luso procura manter os laços com a portugalidade no que será coadjuvado pela existência de uma série de organizações culturais e filantrópicas: “Torna-se preponderante afirmar que a quase totalidade das atividades realizadas pelas instituições de carácter associativo luso não tinha apenas como propósito integrar os portugueses nas comunidades de acolhimento, mas, sobretudo, partilhar entre os compatriotas as sociabilidades representativas mais vinculadas a Portugal. Procuravam através da música, da poesia, do teatro e da leitura vias para manter e valorizar a identidade cultural portuguesa" (CARVALHO, 2011:161).

Um outro contributo importante para o estudo da presença dos portugueses na Amazónia, e também particularmente na cidade de Belém, tem vindo a ser dado com a realização em Portugal e no Brasil de diversos "Seminários Internacionais sobre Migração Portuguesa para o Brasil” (SARGES, SOUSA et al., 2010). Pesquisadores de ambas as nacionalidades têm procurado investigar os arquivos históricos e jornalísticos, relatos de viajantes e bibliografia portuguesa desde o século XVI. No entanto, para o presente projeto, interessa-nos destacar a pesquisa que tem sido feita especificamente sobre Belém do Pará e o modo 
como acolhe a imigração portuguesa dos finais do século XIX e século XX, coincidindo com o ciclo económico da extração e produção da borracha, que dará origem a uma cultura das elites paraenses ao estilo da belle époque parisiense (COELHO, 2011).

Esses estudos, que nos serão de grande utilidade na construção do presente objeto de investigação (SOUSA et al., 2011), não respondem, porém, ao que almejamos investigar, ou seja, encontrar as principais características dos imaginários da imigração lusa para Belém do Pará nas suas zonas de contacto e hibridação com a cultura local. São, no entanto, de grande valor por traçarem a dimensão e natureza do fenómeno migratório português na cidade nos mais de últimos 100 anos.

De acordo com Cancela e Barroso (2010), em Belém, no período de 1908 a 1920 “(...) em um de cada cinco casamentos, havia portugueses com pelo menos um dos cônjuges" (p.33). E acrescenta: "o fluxo migratório dos portugueses ao Brasil foi, no entre séculos, constante e numericamente expressivo para diversas províncias, com destaque para o Rio de Janeiro e para o Pará” (ibidem).

Já Carvalho afirma perentoriamente: "Na origem aldeã de muitos imigrantes, o português atendia ao perfil da preferência das autoridades paraenses. Contudo, a constatação vai ser que os portugueses, ao chegar ao Estado fizeram opção, de forma nítida e numericamente expressiva, pela capital do Estado. Poucos foram aqueles que seguiram para o interior, fosse com destino às colónias agrícolas, fosse com destino a cidades dispersas nesse imenso quinhão amazónico" (CARVALHO, 2011:202).

Além disso, sabe-se que os portugueses se encontravam nessa época ligados sobretudo ao comércio e constituíam um grupo ‘heterogéneo’ (“grandes empresários e banqueiros, envolvidos com o comércio da borracha, até pequenos comerciantes e produtores rurais" (CANCELA \& BARROSO, 2010:33)).

No estudo de Cancela e Barroso, que incidiu sobre os casamentos civis destes portugueses na cidade de Belém, a presença lusa é apresentada como maioritariamente masculina (casaram-se no período estudado, 1908-1920, 769 noivos e apenas 253 noivas). O padrão encontrado revela, igualmente, que as mulheres portuguesas casam maioritariamente (80\%) com noivos portugueses, mas o contrário não é verdadeiro: apenas $26,4 \%$ dos homens portugueses casou com mulheres portuguesas, o que também se encontra ligado à disparidade numérica entre ambos os grupos.

De qualquer modo, a tendência encontrada na análise destes registos de casamento, mas também de outra documentação da época, permite aos 
autores concluir que prevaleceu uma tendência para a "homogamia nas alianças matrimoniais, envolvendo os imigrantes portugueses" (p.32).

Por fim, sublinhe-se que o estudo, ao analisar as profissões dos nubentes por género, encontrou os seguintes resultados: enquanto os homens detém nas suas mãos grande parte do comércio internacional e parte do comércio a retalho, bem como serviços (alfaiates, carpinteiros, artistas, comerciantes, médicos, advogados, entre outros), a atividade das mulheres padece de 'invisibilidade' e de 'desvalorização' (p.39), presumindo os pesquisadores que das $86 \%$ de mulheres que se declaram 'domésticas', as mais pobres seriam empregadas domésticas.

Já no ano de 1923 os dados apresentados referem que no Consulado de Portugal estavam registados cerca de 3500 portugueses, dos quais só 188 mulheres. De entre estas, 118 declaravam-se domésticas, 33 serviçais, 11 lavadeiras e 8 costureiras.

O que daqui se destaca é a invisibilidade destas mulheres portuguesas, algumas das quais têm descendentes diretos nas comunidades que ainda hoje habitam o centro histórico de Belém do Pará.

Refira-se que não só as ressignificações atuais deste rico património imaterial nos interessam, mas também queremos seguir na inspiração dos trabalhos seminais de Paes Loureiro (LOUREIRO, 2000) sobre as modalidades de hibridização destes imaginários com modos particulares de vivenciar a cultura Amazónica. Neste contexto escolhemos estudar as representações e imaginários destes sujeitos, bem como os modos de vivência concreta (porventura 'contaminada' com a amazónica e essa será a nossa hipótese de trabalho) da temporalidade social e cultural, que ainda se identificam com traços da cultura portuguesa.

\section{UMA HERMENÊUTICA MÍTICA DOS IMAGINÁRIOS CULTURAIS - DE KANT E LACAN A EDUARDO LOURENÇO}

Neste projeto de trabalho usaremos o conceito teórico de imaginação e imaginário de Eduardo Lourenço (BAPTISTA, 2003), o qual se elaborou em discussão com as principais conceções teóricas sobre o imaginário desenvolvidas na história moderna da cultura ocidental.

Assim, iniciaremos a reflexão sobre este conceito (um dos que é estruturante desta pesquisa) com a noção Kantiana de imaginação e criação (KANT, 1974), à qual se contrapõem as perspetivas de Nietzsche (NIETZSCHE, 1996), Schopenhauer (SCHOPENHAUER, 1942) e Freud (FREUD, 2001) sobre este tema, e que confluem em Bachelard. As conceções de imaginário de Sartre 
(SARTRE, 1986), Durand (DURAND, 1992), Lacan (LACAN, 1966; LACAN 1971) e Castoriadis (CASTORIADIS, 1995) são igualmente convocadas nesta revisão de literatura, de modo a atingirmos o sentido mais complexo que Eduardo Lourenço confere à 'hermenêutica mítica' como modo de abordar o imaginário cultural (conceito que se articula teoricamente com a conceção de uma 'poética do imaginário’ para a cultura amazónica que Paes Loureiro (LOUREIRO, 2000) propõe por via de uma 'iluminação poética dos mitos').

Recusando a conceção freudiana de imaginário enquanto 'pura ilusão', afirma Eduardo Lourenço que "o imaginário e a sua função na arquitetura global do que chamamos o nosso destino, não se situa no simples prolongamento do real, como sublimação ou compensação da sua ausência” (LOURENÇO, 1999: 14), tratando-se antes de uma “(...) realidade que, literalmente, se define por não ser real (...)" (ibidem): "Se o nosso rei Sebastião faz realmente parte do imaginário português, como Joana d'Arc do francês, não é como figura da perda ou do sacrifício que num dado momento foram derrota ou martírio históricos, mas como figuras que transfiguram já no mero plano histórico esse real, e, mais importante do que isso, condicionaram na sua ordem as manifestações mais decisivas dessa realidade, impondo-lhe uma necessidade e uma energia que nada têm que ver com a da lei que rege os fenómenos ou a energia que os suscita" (ibidem).

Desta forma, para o filósofo português, é o plano do Simbólico (e ainda mais especificamente, do significante) que engendra verdadeiramente o Real e o condiciona, a partir de um plano Imaginário, este que é, em si próprio, o 'não ser real'.

No que respeita a este 'não ser real', “(...) importa pouco saber que processos, do inconsciente ou do consciente, estão na origem e sustentam aquilo que Gilbert Durand, na sequência de Jung, chama 'as estruturas elementares do imaginário" (ibidem), sendo apenas decisivo que ele constitua “ (...) aquela espécie de reservatório de imagens, mais visão e mais vidas que as dos sonhos, mas tão dinâmicas como eles que em vez de serem transformação ou simulacro da cena real têm o poder de a orientar e de lhe conferir um sentido que a sucessão da vida empírica não comporta" (ibidem) .

Lourenço afasta-se assim, simultaneamente, tanto da conceção freudiana como jungeana e durandeana de Imaginário, para nos remeter para um conceito de Imaginário que, embora participe do mundo mítico-simbólico, não se confunde com ele, pois que lhe é anterior e o funda: "O espaço do imaginário, individual ou coletivo, não tem essa espécie de existência idealmente objetiva que os mitos possuem. Não é um mundo que se contempla, é um mundo que nos invade e no qual estamos imersos enquanto esse imaginário existe” (op.cit, p.15). 
De resto, é apenas ao nível desse fundo de imagens que designamos por Imaginário que faz algum sentido colocar-se a questão da identidade que definiria uma dada cultura, embora com ela não se possa confundir, pois “(...) o cultural não é o imaginário, é a parte visível de um iceberg, cuja massa se encontra imersa num oceano de tempo imemorial ou como tal vivido. É isso que faz com que um imaginário exista" (op.cit, p.23).

Em suma, para Lourenço, a questão da identidade (e muito especialmente a da identidade cultural) coloca-se, em primeiro lugar ao nível do Imaginário, que condiciona os Mitos e os Símbolos, estruturando de uma forma particular o plano surreal (porque não empiricamente real nem puramente irreal), que é a Cultura.

Compreende-se assim, que uma tal forma de entender a questão do Imaginário, nas suas relações com os planos Simbólico e Real, condicionem profundamente o modo como se irá analisa a questão identitária neste trabalho, quer portuguesa quer amazónica e brasileira.

Com efeito, é a partir da noção de imaginário e de imaginação como luta, conquista de si por si, sempre precária, e no limite, tarefa de elaboração identitária impossível de se esgotar, que melhor podemos compreender a emergência dos processos de ressignificação cultural da identidade de comunidades e grupos, como aquele que estudámos em Belém do Pará: famílias de imigrantes portugueses e seus descendentes.

\section{INVESTIGAÇÃO DE CAMPO - METODOLOGIA E CARACTERIZAÇÃO DOS SUJEITOS}

A investigação que desenvolvemos usou uma metodologia qualitativa, especificamente recorrendo a entrevistas em profundidade junto de famílias de imigrantes portugueses em Belém do Pará. Os sujeitos foram selecionados por 'bola de neve', que só se deteve quando foi atingida a saturação do grupo de sujeitos.

A realização das entrevistas coletivas e em profundidade foi acompanhada de observação etnográfica e de recolha de material documental (fotos, recortes de jornais, peças de vestuário, receitas de culinária, etc.), que nos foi facultado pelos sujeitos no decorrer do trabalho de campo.

O tratamento e discussão deste material foi feito por análise de conteúdo (BARDIN 1977, GUERRA 2006; PAILLÉ \& MUCCHIELLI, 2013), procurando reconstruir os imaginários e representações da portugalidade junto destas comunidades, em confronto com os principais paradigmas teóricos relativos 
aos conceitos de imaginário/imaginação, identidade e hermenêutica mítica, que apresentámos em momento anterior deste estudo.

Foram cinco as famílias alargadas que entrevistámos, sujeitos que foram eles próprios imigrantes de primeira geração e/ou descendentes destes e que acederam partilhar connosco a história da sua própria imigração ou dos seus ascendentes, referindo-se particularmente à repercussão desses trajetos nas suas próprias vidas e na vida dos seus descendentes e ouros familiares. As entrevistas de grupo forma realizadas nos meses de Junho e Julho de 2016 e a origem geográfica dos imigrantes portugueses situou-se no triângulo Porto/Viseu/ Aveiro.

A estrutura das entrevistas, que começavam por se dirigir ao imigrante de primeira geração ou seu descendente direto, mas que se iam alargando a toda a família à medida que a entrevista se aprofundava, contou com cerca de 3 a 5 membros em simultâneo, abarcando filhos, noras, genros, esposas, netos. De entre as cinco famílias que estudámos duas eram famílias reconstituídas (tinha ocorrido um $2^{\circ}$ casamento na vida do emigrante de $2^{a}$ geração ou descendente direto), 4 delas eram imigrantes por razões económicas e 1 por necessidade de exílio intelectual e político. Todas elas tinham emigrado para Belém do Pará entre as décadas de 40 e 60 do século XX. Em 4 das famílias o emigrante de primeira geração e figura mais proeminente e fundadora de uma certa identidade de 'emigrante português' era do sexo masculino e apenas uma do sexo feminino, esta entretanto já falecida, pelo que os primeiros sujeitos que entrevistámos em todas as famílias foram do sexo masculino. No tempo de que dispúnhamos para completar esta investigação não nos foi possível encontrar famílias onde as mulheres imigrantes portuguesas de primeira geração ou as suas descendentes ocupassem o lugar de 'herdeiras da tradição de imigração portuguesa' em Belém do Pará.

Nas cinco famílias estudadas, nas quais todos os membros entrevistados se auto-identificaram como 'emigrante português' ou seu descendente encontramos situações de todos os tipos: sujeitos com nacionalidade portuguesa, sujeitos com dupla nacionalidade (portuguesa e brasileira) ou sujeitos apenas brasileiros. Estes últimos revelaram sempre a vontade de adquirir a dupla nacionalidade, lusa e brasileira.

A condição económica e social das cinco famílias estudadas era média alta ou alta, exceto num caso em que a família pertencia notoriamente à classe baixa (curiosamente, trata-se daquela onde a mulher portuguesa era considerada fundadora da portugalidade da família). 
Do ponto de vista da escolaridade, todos os sujeitos que entrevistámos tinham frequentado o ensino superior, técnico ou universitário. No entanto, aquele que atingiu um nível mais elaborado de produção cultural e criativa, fazendo atualmente disso a sua profissão é precisamente o descendente do emigrante exilado por razões políticas e intelectuais. Todos os restantes estão ligados, quer a profissões técnicas (caso do descendente da mulher emigrante portuguesa), quer comerciais, empresariais ou ao funcionalismo público.

Refira-se que, das cinco famílias estudadas só aquelas com atividade comercial e empresarial ou em funções públicas participam em atividades promovidas pelas associações de imigrantes em Belém do Pará (designadamente no Grémio Literário, entre outras). As outras duas não participam por razões diferentes: aquela cuja razão principal para emigrar foi de índole política e intelectual, por desinteresse; a outra por não ter recursos suficientes para poder tornar-se sócio de nenhuma delas.

A estrutura das entrevistas passou pelos seguintes focos temáticos: a vida em Portugal antes da decisão de emigrar - família e quotidiano; a decisão de partir; a viagem para o Brasil - o que fica em Portugal, a viagem propriamente dita e o que se encontra no Brasil; a nova vida - dificuldades, oportunidades, ruturas e continuidades, trabalho e lazer, a nostalgia do que ficou; regressos temporários e definitivos.

\section{IMAGINÁRIOS DA IMIGRAÇÃO PORTUGUESA EM BELÉM DO PARÁ - ANÁLISE E DISCUSSÃO}

Após a análise dos dados que recolhemos podemos concluir que as cinco famílias que entrevistámos, apesar das suas diferenças socioeconómicas e da diversidade das suas histórias de vida apresentam em comum um imaginário da portugalidade muito semelhante. De acordo com os discursos que recolhemos, Portugal é imaginado como um país seguro, lindo, limpo, próspero, tranquilo, educado com costumes ancestrais e uma gastronomia única. Curiosamente, estas características não dependem do grau de conhecimento que os sujeitos têm do país. Na verdade, muitos deles nunca visitaram Portugal (descendentes de imigrantes de primeira geração) ou já há décadas que deixaram o país sem nunca terem tido oportunidade de regressar desde então. De qualquer modo, revelam um imaginário idílico da portugalidade, que é sempre acompanhado do desejo de regresso a Portugal, 'um dia'.

Em nossa opinião, este imaginário de um Portugal idílico ao qual se pretende regressar 'um dia', pode ser compreendido à luz de uma das mais constantes 
dimensões da cultura portuguesa: o carácter utópico e messiânico dos discursos sobre a portugalidade, de pendor claramente judaico-cristão (BOTELHO, 1990).

Um outro aspeto muito interessante, que pode ser detetado nos discursos que recolhemos junto das famílias que entrevistámos, é o facto de a origem ou as causas da imigração para o Brasil serem sistematicamente recalcadas ou ocultadas. Em nenhuma das entrevistas a memória de um Portugal pobre e sem oportunidades foi considerado como causa para a migração, embora na memória destas famílias esteja a extração rural e o facto de terem estudado muito pouco em Portugal (como de resto a bibliografia sobre este assunto confirma (ANDRADE, FERLINI, MATOS, (orgs.), 2013; EMMI, 2003)). De qualquer modo, os sujeitos consideram prevalentemente a vida bucólica e tranquila que se vivia em Portugal nos campos, montes e serras, sendo apenas a 'carta de chamada' de algum familiar já no Brasil a origem da decisão de emigrar. Deste modo, encontramos generalizadamente junto dos nossos sujeitos uma espécie de mito de origem na sua condição de emigrante, remetendo para o que Lacan considera a dimensão recalcada e não-dita do Real: o Real é produzido através da dimensão Simbólica, que se deixa impregnar pela dimensão do Imaginário.

É, assim, sem surpresa, que encontramos nestes sujeitos um discurso criado através deste 'não ser real' (o Imaginário) densamente determinado pela dimensão Simbólica. Com efeito, na geografia imaginária e afetiva destas famílias de imigrantes em Belém do Pará encontram-se os marcadores da portugalidade mais comuns: a bandeira portuguesa, o galo de Barcelos, Nossa Senhora de Fátima, a Torre de Belém, o Mosteiro dos Jerónimos, Santo António, o bacalhau e o vinho, o equipamento da seleção portuguesa de futebol, etc.

Mas o que encontramos nos discursos e performaces dos nossos sujeitos, para quem ser português não depende do lugar de nascimento, nem da nacionalidade ou sequer de alguma vez ter visitado o país, é que a identidade portuguesa destes imigrantes é algo com que se é 'contaminado' ou se 'contamina' toda uma família e sua descendência, transcendendo o espaço e o tempo, numa espécie de supraidentidade que afeta todas as áreas da vida. Com efeito, os nossos sujeitos são (re) conhecidos socialmente como 'o português', numa identidade que se lhes cola à pele e que eles procuram também incorporar (muitas vezes literalmente usando chapéus 'portugueses', 'paletós', equipamento da seleção portuguesa de futebol, etc.), aumentando a sua visibilidade na cidade de Belém, enquanto 'verdadeiros portugueses'.

Com efeito, é neste imaginário da portugalidade, que cria os seus próprios símbolos e mitos, que se desenvolve uma hiperidentidade portuguesa, que se estrutura de forma muito evidente no plano do surreal (LOURENÇO, 1999). 
Entre estes mitos, alguns dos que os nossos sujeitos referiram de forma praticamente unânime, destaca-se aquele que remete para a ideia de que todos os portugueses imigrantes em Belém são 'sérios', 'trabalhadores', 'empreendedores' e 'com sucesso' (quanto aos pobres, de acordo com o discurso de um dos nossos sujeitos, seria a própria comunidade de portugueses que se encarregaria de lhes pagar a viagem de regresso para Portugal (cf. Entrevista 5). E a verdade é que a esmagadora maioria dos 'portugueses' que têm visibilidade na Cidade de Belém pertencem, de facto, a uma classe média ou média alta, tendo sido muito difícil encontrar o único sujeito descendente de famílias portuguesas imigrantes que claramente não pertença a este estrato. A hipótese que colocamos é que os eventuais portugueses pobres, que emigraram nas décadas de 40 e 50 para Belém, se diluíram no tecido mais geral da população brasileira, não tendo deixado uma mitologia portuguesa particular inscrita na cidade.

Deste modo, apesar de a população emigrante portuguesa em Belém ter sido no século XX uma população de comunidades pobres e precárias, foi possível compreender a ressignificação identitária entretanto efetuada, sendo hoje, de um modo geral, 'português' sinónimo de bem-estar económico e sucesso empresarial, facto que não esconde a luta intensa desta comunidade pelo reconhecimento na cidade de Belém do Pará, contra o estereótipo e a descriminação, que não deixaram de viver, e que só muito rápida e superficialmente alguns dos nossos sujeitos referem ter vivido.

A hermenêutica mítica a que aqui procedemos, ao abordar os processos de ressignificação identitária que encontramos nos discursos dos nossos sujeitos, não deixa também de dialogar, por vezes dificilmente, com a identidade local de Belém, uma cidade do Norte do Brasil. Com efeito, a identidade da população brasileira dos trópicos é muitas vezes referida pelos nossos sujeitos de forma oposta à identidade portuguesa (na forma de trabalhar, de organizar o tempo e a cidade, de educar os filhos, etc.). Mas, de forma ambígua, e muitas vezes sem plena consciência disso, os nossos sujeitos consideram-se totalmente integrados na sociedade brasileira, quer dizer, também 'totalmente brasileiros' (entrevista 4).

De resto, a organização do tempo de trabalho e de lazer é o que, na opinião da esmagadora maioria dos nossos sujeitos distingue 'o modo de ser dos portugueses' no contexto da sociedade brasileira, uma vez que é unânime a descrição do tempo de trabalho como uma jornada contínua ('sempre em paletó'(entrevistado 2)) de $2^{\mathrm{a}}$ a a domingo, tendo apenas o domingo, a partir do almoço em família, e a tarde disponíveis para descanso, convívio, frequentar a Igreja e o Grémio Literário Português - ou outra associação de portugueses - e ouvir os relatos de futebol na rádio portuguesa, e, mais tarde, assistir à RTP internacional. 
Procurando não ter praticamente nenhuma atividade pública de intervenção na vida política brasileira, a maioria dos portugueses com quem falámos e seus descendentes privilegia sobretudo uma educação sólida para os seus filhos, confiando esta tarefa maioritariamente às instituições de ensino católicas na cidade.

Já quanto às mulheres desta comunidade emigrante durante o século XX, pensamos que seria necessário um estudo bem mais aprofundado nesta matéria de forma a visibilizar o seu papel, influência e importância, quer junto dos negócios 'dos maridos' quer no que respeita à educação dos filhos, participação e mediação face à comunidade envolvente, bem como na conservação e ressignificação das memórias da portugalidade nestas famílias. De qualquer modo, não podemos deixar de sublinhar dois momentos distintos nas formas de promoção dos casamentos nesta comunidade: se num primeiro momento até à década de 40/50 do século XX os homens imigrantes portugueses regressavam a Portugal para casar com uma mulher portuguesa e a levavam para o Brasil (ou procuravam casar com alguma mulher solteira portuguesa em Belém) no intuito de manter intacta uma 'certa forma de ser portuguesa na família e na forma de educar os filhos' ("as mulheres portuguesas são sempre donas de casa e menos folgadas que as outras" - entrevistado 2), a partir de então os casamento mistos passam a ser muito mais comuns, embora isso não signifique necessariamente uma diluição da família na identidade brasileira. Ao contrário, nos sujeitos por nós estudados, a condição do 'homem emigrante português' derrama-se por toda a família e passa a condicioná-la.

Em suma, todos os sujeitos que entrevistámos concordam com o facto de a cidade de Belém do Pará ter constituído uma oportunidade de viver num país a crescer, onde tudo estava por fazer e onde as oportunidades de crescimento e prosperidade são muitas. Mas, a par delas, não deixam de sublinhar as dificuldades: a jornada contínua de trabalho, o risco da falta de preparação e escassez de capital, e sobretudo o facto de "não estarmos no nosso país" (Entrevista 3).

\section{DIÁSPORA E IMAGINÁRIOS DA PORTUGALIDADE}

No final do nosso estudo podemos concluir com alguma segurança que a identidade dos sujeitos por nós entrevistados passa essencialmente pela rutura com Portugal, o país físico, mas não com o simbólico ou imaginário (hoje os canais portugueses de televisão e as associações têm grande importância). Com efeito, os nossos sujeitos revelam os seus imaginários da potugalidade através da dimensão simbólica, de que estão constantemente rodeados. Mais do que isso:

Novos Cadernos NAEA • v. 20 n. $1 \cdot$ p. 9-24 • jan-abr 2017 
a portugalidade parece contagiar todos os elementos da família, mesmo os que nunca estiveram em Portugal.

A sua identidade pessoal e individual também é totalmente contaminada pela portugalidade. Os sujeitos são conhecidos como 'o português', quase perdendo o nome próprio: a nacionalidade equivale à identidade, tanto do ponto de vista social como na autopercepção. O seu tempo livre esgota-se na portugalidade, afastando-se de uma atividade política mais visível, autorrepresentando-se como uma comunidade séria, trabalhadora e bem-sucedida: “aqui não há portugueses pobres"! (entrevista 3)

A Brasil, enquanto terra de oportunidades, é visto como um lugar de gente 'pouco educada' (entrvista 4), porém, paradoxalmente com excelentes oportunidades de educação, que os próprios imigrantes tudo fazem para proporcionar aos filhos (entrevista 5).

Para os portugueses imigrantes em Belém do Pará objecto do nosso estudo, o trabalho esgota todo o tempo disponível, o que sobra é dedicado a solidificar redes de contactos dentro da comunidade, em primeiro lugar para fortalecer parcerias socio-económicas (segundo nos foi constantemente sublinhado, o grande problema dos portugueses é a falta de capital para investir).

As mulheres, quer imigrantes quer casadas com imigrantes, embora omnipresentes, são invisibilizadas, apesar de elas serem as detentoras de um 'saber português' (que trazem de Portugal ou, no caso de brasileiras, que procuram aprender para participarem - no caso das famílias que estudamos, de forma muito entusiasmada - na identidade portuguesa dos seus maridos). Este 'saber português' passa pela gastronomia, pelas rendas e bordados, pela música, pela religião, pelas festas e tradições portuguesas, pela educação dos filhos e pelo papel tradicional de 'ajudar os maridos à sua sombra e com humildade' (entrevista 2), o que na prática significa trabalhar tanto como os homens e enfrentar ainda uma dupla jornada de trabalho em casa (entrevistas 3 e 4).

Até aos anos 40/50, por regra, os casamentos da comunidade de imigrantes em Belém eram endogâmicos. Os nossos sujeitos confirmam os dados que encontrámos na revisão de literatura: mais recentemente, e sobretudo nas $2^{\mathrm{a}} \mathrm{s}$ gerações, os casamentos são mistos e as recordações acentuam-se através dos relatos dos mais velhos e dos objetos que a família conserva (que podem ir da simples fotografia até ao mobiliário da casa). Nestas últimas famílias percebemos que aumenta o desejo dos regressos definitivos. Mas este são regressos sempre sonhados e nunca concretizados, constituindo nos discursos dos sujeitos imigrantes portugueses que estudámos uma espécie de 'litania pela terra prometida', mas que nunca chega a ser alcançada. 
Como afirma Stuart Hall,

Trata-se, é claro, de uma conceção fechada de 'tribo', diáspora e pátria. Possuir uma identidade cultural nesse sentido é estar primordialmente em contato com um núcleo imutável e atemporal, ligando ao passado o futuro e o presente numa linha ininterrupta. Esse cordão umbilical é o que chamamos de 'tradição', cujo teste é o de sua fidelidade às origens, sua presença consciente diante de si mesma, sua 'autenticidade'. É, claro, um mito - com todo o potencial real dos nossos mitos dominantes de moldar nossos imaginários, influenciar nossas ações, conferir significado às nossas vidas e dar sentido à nossa história. Os mitos fundadores são, por definição, transistóricos: não apenas estão fora da história, mas são fundamentalmente a-históricos. São anacrónicos e têm a estrutura de uma dupla inscrição. Seu poder redentor encontra-se no futuro, que ainda esta por vir (HALL, 2003:29-30).

\section{BIBLIOGRAFIA}

ARAGÓN, L. E. (Ed.). (2009). Migração Internacional Pan-Amazôniana. Belém do Pará: UFPA/NAEA

ANDRADE, J. J. d., FERLINI, A. V. L. A., MATOS, M. 1. S. d., \& [orgs.], F. d. S. (Eds.). (2013). De Colonos A Imigrantes- I(E)migração portuguesa para o Brasil. S. Paulo: Alameda Editora.

ARAGÓN, L. E. (Ed.). (2009). Migração Internacional Pan-Amazôniana. Belém do Pará: UFPA/NAEA.

BAPTISTA, M. M. (2003). A paixão de compreender em Eduardo Lourenço. Porto, Asa.

BARDIN, L. (1977). Análise de Conteúdo. Lisboa, Edições 70.

BOTELHO, A. (1990). Da Saudade ao Saudosismo. Lisboa: Instituto de Cultura e Língua Portuguesa.

CANCELA, C. D., \& COSME, J. S. R. (2016). Entre fluxos, fontes e trajetórias: imigração portuguesa para uma capital da Amazônia (1850-1920). Estudos Ibero-Americanos, 42(1, jan.-abr.), 232-254.

CANCELA, C. D. \& D. S. BARROSO (2010). Imigração portuguesa e casamento: um olhar a partir do gênero, da geração e da actividade (Belém, 1980-1920). Entre Mares - O Brasil dos portugueses. M. N. SARGES, F. SOUSA, M. I. MATOS, A. O. V. JUNIOR and C. D. C. (orgs.). Belém, Editora Paka-Tatu: $32-$ 41. 
CANCELA, C. D., \& COSME, J. S. R. (2016). Entre fluxos, fontes e trajetórias: imigração portuguesa para uma capital da Amazônia (1850-1920). Estudos Ibero-Americanos, 42(1, jan.-abr.), 232-254.

CARVAlHO, M. A. d. (2011). Bebendo açaí, comendo bacalhau: Perfil e práticas da sociabilidade lusa em Belém do Pará entre finais do século XIX e início do século XX. PhD, Faculdade de Letras da Universidade do Porto.

CASTORIADIS, C. (1995). A Instituição Imaginária da Sociedade. Rio de Janeiro, Paz e Terra.

COELHO, G. M. (2011). "Na Belém da belle époque da borracha (1890-1910): dirigindo os olhares." Escritos 5 5(5): 141-168.

DURAND, G. (1992). Les Structures Antropologiques de L'Imaginaire. Paris, Dunod.

EMMI, M. F. (2003).AAmazônia como destino das migrações internacionais do final do século XIX ao início do século XX : o caso dos portugueses. Campinas. www.abep.nepo.unicamp.br/encontro2010/docs_pdf/tema_1/ abep2010_2086.pdf

FREUD, S. (2001). Totem e Tabu. Lisboa, Relógio d’Água.

GUERRA, I. C. (2006). Pesquisa qualitativa e análise de conteúdo: sentidos e formas de uso. Estoril, Princípia.

HALL, S. (2003). Identidades e Mediações Culturais. Belo Horizonte: UFMG. HEIDEGGER, M. (1986). Être et Temps. Paris, Gallimard.

HEIDEGGER, M. (1992). A Origem da Obra de Arte. Lisboa, Edições 70.

KANT, E. (1974). Critique de la Faculté de Juger. Paris, Vrin.

LACAN, J. (1966). Écrits I. Paris, Éd. du Seuil.

LACAN, J. (1971). Écrits II. Paris, Éd. du Seuil.

LOUREIRO, J. d. J. P. (2000). Cultura Amazónica - uma poética do imaginário. S.Paulo, Escrituras Editora.

LOUREIRO, J. d. J. P. (2007). A Conversão Smiótica na arte e na cultura. Belém do Pará, Editora Universitária UFPA.

LOURENÇO, E. (1999). A Europa e a Questão do Imaginário - A Europa e o (Seu) Imaginário. Do Mundo da Imaginação à Imaginação do Mundo Festival do Imaginário, Abrantes, 8 a 17 de Novembro de 1996. AAVV. Lisboa, Ed. Fim de Século: 13-24. 
LOURENÇO, E. (2004). Sobre o Tempo. Cartografia Imaginária de Eduardo Lourenço - dos Críticos. M. M. B. (coord.). Maia, Ver o Verso: 13-19.

NIETZSCHE, F. (1996). O Nascimento da Tragédia ou o Mundo Grego e Pessimismo. Obras Escolhidas de Nietzsche. A. M. (ed.). Lisboa, Círculo de Leitores. I: 5-178.

PAILLÉ, P., \& MUCCHIELLI, A. (2013). L'Analyse Qualitative en Sciences Humaines et Sociales (3eme ed. ed.). Paris: Armand Colin.

SARGES, M. d. N., F. d. SOUSA, M. I. MATOS, A. O. V. JUNIOR and C. D. C. (orgs.), Eds. (2010). Entre Mares - O Brasil dos portugueses. Belém, Editora Paka-Tatu.

SARTRE, J.-P. (1986). L'Imaginaire. Paris, Folio.

SCHOPENHAUER (1942). Le Monde Comme Volonté et Comme Représentation. Paris, PUF.

STEINER, G. (1981). Martin Heidegger. Paris, Flammarion.

SOUSA, F. D., MARTINS, I., MENEZES, L. M. D., MATOS, I., ARRUDA, J., SARGES, N., \& FERLINI, V. (Eds.). (2014). Portugal e as migrações da Europa do sul para a América do sul. Porto: Editor CEPESE - Centro de Estudos da População, Economia e Sociedade.

SOUSA, F. d., MARTINS, I., MENEZES, L. M. d., MATOS, M. I., SARGES, M. d. N., \& SILVA, S. S. (Eds.). (2011). Um Passaporte para a Terra Prometida. Porto: Esfera do Caos.

SOUSA, F. d., MATOS, I. d. L., \& MATOS, I. (Eds.). (2009). Nas duas margens. Os portugueses no Brasil. Porto: Edições Afrontamento.

\section{Webgrafia}

http:/ / estudosculturais.blogspot.pt http://buscatextual.cnpq.br/buscatextual/visualizacv.do?id=K4782343A4 http://buscatextual.cnpq.br/buscatextual/visualizacv.do?id=K4777690U4 http://buscatextual.cnpq.br/buscatextual/visualizacv.do?id=K4767640H4 http://dx.doi.org/10.15448/1980-864X.2016.1.21580 